\title{
O princípio da capacidade contributiva e suas relações com a seletividade no âmbito do Imposto sobre Produtos Industrializados
}

\author{
Fernanda Fabiana Scarparo ${ }^{1}$
}

\begin{abstract}
Resumo
O presente artigo visa discorrer sobre o princípio da capacidade contributiva e a relação existente entre ele e a seletividade no âmbito do Imposto sobre Produtos Industrializados. Para tanto, primeiramente faz-se mister uma breve análise da regra matriz desse tributo, de modo a mencionar seus critérios material, temporal e espacial, além dos critérios atinentes à relação jurídica tributária - critérios pessoal e quantitativo, para somente então adentrar no objeto a que este se propõe. A partir de então, destina-se a efetuar uma apreciação sobre se ocorre ou não a realização do princípio da capacidade contributiva quando da utilização de alíquotas seletivas.
\end{abstract}

Palavras-Chave: IPI; Princípio da capacidade contributiva; seletividade.

\section{Introdução}

O objeto do presente estudo é analisar o princípio da capacidade contributiva no âmbito do Imposto sobre Produtos Industrializados, e sua relação com o princípio da seletividade aplicado aos produtos tributados por esse imposto.

Para tanto, indispensável analisar a regra matriz de incidência fiscal desse tributo especificamente, posto que já em seu critério material se verifica uma série de conflitos entre doutrina e jurisprudência.

Em seguida, preponderante tecer breves esclarecimentos quanto a termos como capacidade contributiva, seletividade e relacionar ambos esses princípios, para então, concluir a idéia propulsora desse escrito.

Segue dessa forma o início desse estudo para que seja possível galgar seu desfecho mediante respaldo doutrinário e do próprio direito positivo.

1 Aluna da graduação do Curso de Direito da Universidade Estadual de Londrina. 


\section{Regra matriz do IPI}

\subsection{Hipótese tributária}

\subsubsection{Critério material}

A competência e a previsão para instituir o imposto sobre produtos industrializados (IPI) estão no artigo 153, IV da Constituição Federal (CF), artigo esse do qual é possível extrair praticamente toda a regra matriz de incidência tributária do IPI. Esse imposto, entretanto, possui regulamentação específica e aprofundada através do Código Tributário Nacional (CTN) e do Decreto 4544/2002 (RIPI). Senão vejamos os artigos correspondentes às normas do artigo 153, IV da CF e do artigo 46 do CTN, dos quais é possível identificar o critério material do IPI:

Art. 153. Compete à União instituir impostos sobre:

[...]

IV - produtos industrializados;

Art. 46. O imposto, de competência da União, sobre produtos industrializados tem como fato gerador:

I - o seu desembaraço aduaneiro, quando de procedência estrangeira;

II - a sua saída dos estabelecimentos a que se refere o parágrafo único do artigo 51; III - a sua arrematação, quando apreendido ou abandonado e levado a leilão.

Parágrafo único. Para os efeitos deste imposto, considera-se industrializado o produto que tenha sido submetido a qualquer operação que lhe modifique a natureza ou a finalidade, ou o aperfeiçoe para o consumo.

Extrai-se dessa forma que, se observada somente a Carta Magna, o critério material do IPI é industrializar produtos. Todavia, do CTN é possível obter três regras-matriz, logo, três critérios materiais - o desembaraço aduaneiro de produtos de procedência estrangeira, a saída de produtos industrializados do estabelecimento industrial, a arrematação de produtos industrializados que foram apreendidos ou abandonados quando levados a leilão.

Essa questão gera grande discussão doutrinária e jurisprudencial, posto que alguns autores, tais como José Roberto Vieira, que menciona o professor Geraldo Ataliba para corroborar seu entendimento (apud VIEIRA, 1993, p. 73), afirma que o critério material desse tributo não é industrializar produtos, mas sim realizar operações jurídicas com 
produtos industrializados, nas quais se verifique a transferência da propriedade ou posse desses (VIEIRA, 1993, p. 73-80). ${ }^{2}$

No que tange ao desembaraço aduaneiro (art. 46, I CTN), percebe-se que o CTN ampliou a hipótese de incidência do IPI em relação ao que fora disposto na CF. Quanto a isso Elali (2004, p. 64) afirma que não é possível a incidência de um tributo sem previsão constitucional, e por isso afirma que essas hipóteses trazidas pelo CTN não podem caracterizar hipóteses de incidência do IPI. Contudo, afirma que o critério material definido na CF é produto industrializado, não importado. O próprio autor cita José Eduardo Soares de Melo, segundo o qual não deve incidir IPI "na importação de quaisquer espécies de bens de produtos, porque além de inexistir industrialização no território nacional, a Constituição já prevê um imposto federal relativo à importação" (MELO apud ELALI, 2004, p. 65).

Outros autores, como Antônio Maurício da Cruz, entendem que somente seria passível de incidência de IPI nesse caso, os produtos industrializados reimportados, até mesmo em vista de evitar fraudes (CRUZ apud VIEIRA, 1993, p. 99). Hugo de Brito Machado (2003, p. 473-476), por sua vez, afirma que "desembaraço aduaneiro" caracteriza apenas o critério temporal do IPI e não seu fato gerador, e que a materialidade do IPI encontra-se no produto industrializado, logo pouco importa se a industrialização tenha ocorrido dentro ou fora do território nacional. Ademais, afirma ainda que a incidência do IPI sobre produtos industrializados de procedência estrangeira não viola discriminação constitucional de competências tributárias, ou seja, que não se está diante de um caso de bitributação, mas sim de um bis in idem. No âmbito jurisprudencial, entretanto, verifica-se o respeito aos casos de incidência previstos no CTN.

Enfim no que tange ao inciso III do art. 46 do CTN, em relação à arrematação, mister mencionar que está em desuso, posto que a Delegacia da Receita Federal tem optado por não realizar leilões. De qualquer forma, caso seja realizado, incidirá o IPI (MACHADO, 2003, p. 477), e por isso pode ser considerado mais uma hipótese de incidência desse tributo. Paulo de Barros entende o imposto cobrado sobre a arrematação faz parte da competência residual da União, vez que a hipótese de incidência está na arrematação (BARROS apud BOTTALLO, 2002, p. 36).

2 O presente artigo coaduna com o entendimento desses autores. 


\subsubsection{Critério temporal}

Conforme o inciso II do artigo 46 do CTN, o critério temporal da incidência do IPI se verifica quando da saída do produto industrializado do estabelecimento industrial, momento no qual se manifesta a operação jurídica realizada com produtos industrializados (VIEIRA, 1993, p. 101). Quanto a esse critério, o próprio autor, em momento posterior afirma que a saída do estabelecimento deve comportar fato jurídico, posto que, conforme exemplos de Baleeiro, Ataliba e Paulo de Barros quando o produto sai do estabelecimento por furto, roubo, caso fortuito ou força maior, não se verifica uma hipótese de incidência do IPI (VIEIRA, 2006, p. 180). Segundo Elali (2004, p. 70), também se realiza o critério temporal no momento do desembaraço aduaneiro e do arremate do produto em leilão.

\subsubsection{Critério espacial}

Tal como enuncia o artigo 153 da CF, o IPI é um tributo cuja competência é outorgada a União. Dessa forma, seus efeitos se alastram por todo o território nacional. Ressalve-se, entretanto as anotações referentes aos produtos industrializados de procedência estrangeira, sobre os quais o fato jurídico se dá pelo desembaraço aduaneiro, logo o critério espacial se realiza nas repartições aduaneiras.

\subsection{Relação jurídica tributária}

\subsubsection{Critério pessoal}

Sem maiores considerações a serem feitas quanto ao sujeito ativo, posto que está claramente evidenciado no artigo 153, IV da CF que é a União.

Os sujeitos passivos desse tributo, segundo a RIPI (Decreto 4544/2002), são os contribuintes e responsáveis. Os responsáveis estão elencados no artigo 25 da RIPI, o qual traz extenso rol de casos em que se opera a responsabilidade. Os contribuintes estão discriminados no artigo 24 do Decreto, cuja redação provém do artigo 51 do CTN, o qual dispõe:

Art. 51. Contribuinte do imposto é:

I - o importador ou quem a lei a ele equiparar;

II - o industrial ou quem a lei a ele equiparar; 
III - o comerciante de produtos sujeitos ao imposto, que os forneça aos contribuintes definidos no inciso anterior;

IV - o arrematante de produtos apreendidos ou abandonados, levados a leilão.

Parágrafo único. Para os efeitos deste imposto, considera-se contribuinte autônomo qualquer estabelecimento de importador, industrial, comerciante ou arrematante.

\subsubsection{Critério quantitativo}

\subsubsection{Base de cálculo}

A base de cálculo do IPI está determinada no artigo 47, incisos I, II e III do CTN. Em síntese, o inciso primeiro desse artigo preceitua que, quando do desembaraço aduaneiro de produto cuja origem seja estrangeira, a base de cálculo será o seu preço em moeda estrangeira, convertido em moeda nacional, segundo cotação do câmbio dessa data (artigo 20, II do CTN), acrescido dos encargos cambiais pagos pelo importador ou que podem ser exigidos dele, taxas exigidas para entrada do produto no país e do imposto de importação.

O inciso II, por sua vez, refere-se à saída do produto do estabelecimento industrial ou equiparado. Nesse caso, a base de cálculo será o valor da operação da qual decorre a saída. Na ausência desse valor, utiliza-se como base de cálculo o preço do produto no mercado atacadista da praça da sede do estabelecimento de onde partiram os produtos sobre os quais recai a tributação.

Por fim, o inciso III do artigo 47 do CTN trata dos casos de arrematação em leilão de produto industrializado, quando apreendido pelo fisco ou abandonado. Nesse caso a base de cálculo será o valor da arrematação.

\subsubsection{Alíquota}

Esse tributo possui alíquotas variáveis segundo o critério da essencialidade dos produtos - conforme dispõem os artigos 153, parágrafo 3, I da CF e 48 do CTN -, ou seja, quanto mais útil, necessário ou essencial à sociedade um produto, menor a alíquota. Ao contrário, quanto menos essencial, mais elevadas as alíquotas. As alíquotas do IPI estão dispostas na Tabela do IPI -TIPI (Decreto n. 4.542/02). 


\section{Princípio da capacidade contributiva}

Segundo Roque Carrazza (2005, p. 84), “o princípio da capacidade contributiva hospeda-se nas dobras do princípio da igualdade e ajuda a realizar, no campo tributário, os ideais republicanos". O princípio da capacidade contributiva está delineado no artigo 145, parágrafo primeiro da $\mathrm{CF}$, segundo o qual: "Sempre que possível, os impostos terão caráter pessoal e serão graduados segundo a capacidade econômica do contribuinte...". De acordo com o professor, é justo que quem possui mais pague na proporção de sua riqueza, assim como quem possui menos deve pagar menos. Afirma ainda que esse princípio "informa a tributação por meio de impostos. Intimamente ligado ao princípio da igualdade, é um dos mecanismos mais eficazes para que se alcance a tão almejada Justiça Fiscal" (CARRAZA, 2005, p. 85). Quanto a esse tema, Carrazza (2005, p. 84-89) segue afirmando que o "destinatário imediato" desse princípio é o "legislador ordinário das pessoas políticas".

\section{Seletividade no direito tributário brasileiro}

A seletividade no Direito Tributário brasileiro se dá em função da essencialidade. Está prevista no artigo 153, parágrafo 3, I da CF, e é obrigatória segundo o preceituado no artigo 155, parágrafo 2, III também da CF. Mediante esse requisito, as alíquotas aplicadas aos produtos, dessa forma, variam de zero a mais de trezentos por cento, conforme os produtos sejam mais ou menos essenciais e, aumentam ainda mais quando de produtos que sejam nocivos à saúde. Segundo Hugo de Brito Machado (2003, p. 487), "a seletividade está também ligada à função extrafiscal do tributo. Tem-se que o tratamento discriminatório é usado quando se pretende, com o tributo" influenciar nas decisões daqueles que são onerados com o seu pagamento.

O autor menciona ainda que a seletividade pode ter outros critérios, dentre eles o da capacidade contributiva, objeto deste trabalho (MACHADO, 2003, p. 489-490).

\section{Seletividade e capacidade contributiva}

Hugo de Brito Machado (2003, p. 490), afirma que a seletividade em função da essencialidade, "funciona indiscutivelmente como instrumento de realização do princípio da capacidade contributiva". Afirma ainda que o princípio da capacidade contributiva é 
atendido, justamente porque o critério da seletividade adotado é o da essencialidade, e naturalmente que há produtos muito mais caros, os quais se destinam prioritariamente a pessoas mais abastadas, ao passo que produtos mais simples e conseqüentemente mais baratos, destinam-se aos mais humildes, ou seja, de menor capacidade contributiva. Aduz que, uma vez que o valor do IPI integra "o preço do produto e, sendo dessa forma suportado pelo consumidor, é correto dizer-se que esse imposto pode realizar adequadamente o princípio da capacidade contributiva" (MACHADO, 2003, p. 490).

Quanto a isso, Laís Vieira Cardoso (2003, p. 256), em artigo publicado no compêndio IPI - aspectos jurídicos relevantes, afirma que "tanto na tributação direta quanto na que ocorre de forma indireta é que a lei de imposição tributária deverá ser editada tomando-se em consideração as características daquele que vai arcar com o seu custo" - o que proporciona uma tributação isonômica. Dessa forma, menciona ainda que essa "tributação isonômica implica em atendimento à capacidade contributiva quando, ao sofrer carga tributaria aquele que arcou com o seu ônus não tenha o seu potencial contributivo reduzido" (CARDOSO, 2003, p. 257).

Carrazza (2005, p. 95) afirma que "o princípio da seletividade tem por escopo favorecer os consumidores finais, que são os que, de fato, suportam a carga econômica do $I P I^{\prime \prime}$. Disso, pode-se depreender que, em vista do dispositivo constitucional que determina a realização do princípio da capacidade contributiva dos indivíduos, a seletividade vem para exteriorizar a sua aplicação no IPI, vez que, através da minoração de alíquotas aos produtos indispensáveis - de primeira necessidade aos indivíduos - e da majoração aos produtos supérfulos ou aos quais se pretende um desestímulo, permite-se aqueles cuja capacidade econômica é menor ter acesso mais fácil aos produtos sem os quais não pode viver.

\section{Conclusão}

Enfim, após a análise Imposto Sobre Produtos Industrializados, através da sucinta apreciação de sua regra matriz, ao anotar seus critérios material, temporal e espacial, tal como os critérios pessoal e quantitativo, foi possível colocar em voga algumas questões de grande dúvida e divergência doutrinária e jurisprudencial sobre esse tributo.

Em seguida, indispensável à abordagem pretendida a esse artigo, esclarecer o princípio da capacidade contributiva, da seletividade, a relação dessa com a essencialidade, 
assim como, principalmente, a relação existente entre a seletividade e a capacidade contributiva.

Posto que a seletividade se dá em função da essencialidade dos produtos, verificase que a essencialidade é o critério para a seleção dos produtos e suas respectivas alíquotas - neste, sempre no âmbito do IPI. Entretanto, como o próprio Hugo de Brito Machado (2003, p. 489-490) considera, a essencialidade pode não ser o único critério a ser adotado, mas que a capacidade contributiva, por exemplo também cabe nessa situação.

Quanto a isso, o entendimento deste trabalho corrobora com o do supracitado autor, assim como com o de Roque Antônio Carrazza. Em vista do dispositivo constitucional 145, parágrafo 1ำ, determinar que os tributos, sempre que possível, terão caráter pessoal e serão graduados conforme a capacidade econômica dos contribuintes, verifica-se que um imposto cujas alíquotas são tão flexíveis deve necessariamente atender a tal dispositivo.

A realização do princípio da capacidade contributiva, tal como dantes citado pelo professor Carrazza é uma das formas de realização do princípio republicano, assim como uma das maneiras mais eficazes de concretização e alcance da Justiça Fiscal. Nada mais justo em um país como o Brasil que aqueles que têm mais, arquem com maior parcela da sustentação do Estado Social, até mesmo por um princípio de solidariedade ao próximo.

Entretanto, alguns produtos imunes, isentos, ou cujas alíquotas sejam zero ou irrisórias, tais como produtos básicos relativos a moradia, alimentação, saúde, vestuário e educação devem ser tributados em razão de sua essencialidade, posto que todos necessitam dessas prerrogativas para viver. A verificação da capacidade contributiva se dá no fato de que, embora todos necessitem, há aqueles que podem comprar esses produtos ou outros mais caros, enquanto outros precisam se restringir a esses pela ausência de melhores condições econômicas. O que deve ser onerado a maior, dessa forma, para atingir o princípio da capacidade econômica dos contribuintes deve ser aquilo que não somente os mais abastados têm condições de adquirir. Neste momento, eximi-se de mencionar o intuito extrafiscal conferido a alguns produtos através de suas alíquotas, posto que isso não visa a capacidade contributiva, mas concretização de políticas públicas de incentivo ou desestimulação de algumas práticas ou consumo de determinados produtos.

Do exposto, entende-se que a seletividade no âmbito do IPI, através do seu próprio critério de seleção - a essencialidade - realiza por fim o princípio da capacidade 
contributiva, de forma direta ou não, mas de forma a favorecer o consumidor final, que é o contribuinte de fato, quando da compra de determinados produtos indispensáveis a sua sobrevivência.

\section{Referências}

BOTTALLO, Eduardo Domingos. Fundamentos do IPI: Imposto sobre Produtos Industrializados. São Paulo: Revista dos Tribunais, 2002.

CARDOSO, Laís Vieira. A seletividade no IPI. IPI: aspectos jurídicos relevantes. Coordenação de Marcelo Magalhães Peixoto. São Paulo: Quartier Latim, 2003.

CARRAZZA, Roque Antônio. Curso de Direito Constitucional Tributário. 21. ed. rev. ampl. atual. até EC 48/2005. São Paulo: Malheiros Editores, 2005.

CASSONE, Vittorio. Direito Tributário: fundamentos constitucionais da tributação, classificação dos tributos, interpretação da legislação tributária, doutrina, prática e jurisprudência, atualizado até EC 42/2003. São Paulo: Atlas, 2004.

ELALI, André de Souza Dantas. IPI: aspectos práticos e teóricos. 1. ed. Curitiba: Juruá, 2004.

FABRETTI, Laudio Camargo. Código Tributário Nacional Comentado. São Paulo: Atlas, 2005.

MACHADO, Hugo de Brito. Comentários ao Código Tributário Nacional. São Paulo: Atlas, 2003.

PEIXOTO, Marcelo Magalhães. IPI: aspectos jurídicos relevantes. Coordenação de Marcelo Magalhães Peixoto. São Paulo: Quartier Latim, 2003.

VIEIRA, José Roberto. A regra matriz de incidência do IPI: texto e contexto. Curitiba: Juruá, 1993.

VIEIRA, José Roberto. Imposto sobre Produtos Industrializados: uma Águia Garciamarquiana entre os tributos. Curso de Especialização em Direito Tributário. FGV - EDESP. São Paulo: Quartier Latin, 2006. 
